\title{
Judíos, comunistas e interbrigadistas: intersecciones y ambivalencias en los años treinta desde un enfoque transnacional
}

\author{
Jews, Communists and International Brigades: Intersections \\ and Ambivalences in the 1930s from a Transnational Perspective
}

José Carlos Rueda Laffond ${ }^{*}$,

\section{RESUMEN}

El artículo estudia al sujeto judío comunista durante los años treinta desde una perspectiva transnacional, explorando las complejas relaciones entre ambas identidades. El texto resalta las particularidades de la militancia comunista judía atendiendo al discurso orgánico de matriz soviética y a la casuística presente en varios contextos geográficos. En su segunda parte analiza, desde un amplio corpus de egodocumentos y del texto de Gina Medem Los judios voluntarios de la libertad, las claves de autoafirmación política y de judeidad en miembros del contingente comunista encuadrado en España en las Brigadas Internacionales. Las conclusiones resaltan el notable peso de la hibridación identitaria y política en este colectivo.

Palabras claves: autobiografía; comunismo; judíos; Guerra Civil española; Brigadas Internacionales.

\begin{abstract}
The article studies the communist Jewish subject during the 1930s from a transnational perspective. It explores the complexity of the relations between the two identities and establishes particularities of Jewish communist militancy, with attention to the official organic discourse of the Soviet matrix and the casuistry in different contexts. In its second part, the article analyses, through egodocuments and political publishing such as Gina Medem's book Los judíos voluntarios de la libertad, the keys to political self-affirmation and Jewishness in members of the communist contingent organized in Spain (International Brigades). The conclusions highlight the notable weight of political hybridization and identity tension in this group.

Keywords: autobiography; communism; Jews, Spanish Civil War; International Brigades.
\end{abstract}

\footnotetext{
* Universidad Complutense de Madrid, Facultad de Ciencias de la Información, Departamento de Historia de la Comunicación Social, Madrid, España. jcrueda@pdi.ucm.es $<$ https://orcid.org/00000002-6138-2968>
} 
Un libro de Martínez Bande (1965, p. 56), afín al relato franquista sobre la Guerra Civil, incorporó una galería de interbrigadistas presentados como "típicamente asiáticos o africanos", "negros, de rasgos orientales, o simplemente de difícil clasificación, aunque nunca españoles". Otro publicista, Mauricio Carlavilla (1973, p. 72), abordó la conexión entre degeneración y “sodomía en su función comunista a través de los siglos" con afirmaciones como "Marx es judío y probablemente también Engels, y esa su raza los hace sagrados para psicoanalistas y homosexualistas". Y Eduardo Comín Colomer explicó las relaciones entre judaísmo y comunismo descifrando la sigla URSS como "Unión Racial de los Sabios de Sión". "El enemigo es potente”, concluía, "pero nosotros tenemos la ventaja suprema de tener a Dios de nuestro lado" (Comín; Botzaris, ¿1952?, p. 82 y 89).

Tales consideraciones fueron piezas epigonales en las tesis del contubernio judeo-comunista, un imaginario supremacista y ultranacionalista plagado de tópicos reflejados en montajes como Le bolchevisme contre l'Europe (1942). Otras visiones antisemitas - la infiltración asiática, el secuestro y muerte de niños, la violencia sexual - acabaron trasplantadas a la campaña de la Democracia Cristiana en las legislativas italianas de abril de 1948, o en las imágenes de hordas de violadores que poblaron la narrativa de la Guerra Fría (Pivato, 2013; Garraio, 2012, p. 47-66).

El mito judeo-comunista se basaba en la idea de una identidad antinacional disgregadora. Paul Hanebrink (2018, p. 4-9) ha puesto de relieve tanto su extensa proyección temporal como su carácter transnacional, así como su ductilidad para adecuarse, como código político-cultural, a condicionantes locales. Las tesis sobre conspiración judeo-comunista en la Alemania nazi manejaron claves y respondieron a requerimientos singulares, diferentes a los movilizados en la noción de contubernio judeo-marxista (y, además, masónico) franquista. Pero, al tiempo, ambas narrativas fueron expresiones de una idea mayor con argumentos apocalípticos, antisemitas y ultranacionalistas.

Al abordar las campañas anticosmopolitas en la Unión Soviética y en las democracias populares durante el tardoestalinismo, Hanebrink (2018, p. 186187) ha subrayado, provocativamente, un aspecto con frecuencia obviado: su profundo y dilatado legado en Europa del Este tras la desestalinización, bien respecto al asentamiento de un imaginario estereotipado - el "falso comunista judío", o el "judío estalinista", como chivo expiatorio -, bien en lo relativo a su uso político, "en términos étnicos", en el debate sobre implementación de un comunismo nacional.

Tony Michels (2016) asimismo ha resaltado el alcance transnacional del 
mito judeo-bolchevique apuntando su pronto manejo en Estados Unidos, por ejemplo a través de la financiación de Henry Ford de la publicación de Los protocolos de los sabios de Sión. Pero ha llamado la atención acerca de la necesidad de trascenderlo y afrontar, como requerimiento interpretativo ante el comunismo norteamericano de los años veinte, el hecho del notable predominio en la base del partido del componente judío, especialmente en Nueva York, como intersección entre "etnicidad y política".

La historiografía ha enfatizado también el carácter transterritorial del proyecto comunista y de algunos colectivos judíos. La perspectiva transnacional, los estudios poscoloniales o los enfoques culturales han resaltado el rol de la Internacional Comunista (IC) y de sus redes de solidaridad o difusión de valores, entendiendo al proyecto comunista como síntesis entre ideal internacionalista, condicionantes locales y proyección global (Dullin; Studer, 2018). También se ha problematizado la visión de control unívoco desde el centro soviético sobre los partidos nacionales, revalorizándose el papel de los intercambios y de las transferencias político-culturales (Laporte, 2013, p. 7-20). La identidad comunista se presentaría así como constructo definido por un canon soviético, pero también por particularidades e hibridaciones, donde convivieron las marcas internacionalistas o anti-imperialistas junto al discurso nacional-bolchevique o el antifascismo patriótico.

Desplazamiento, transterritorialidad o cosmopolitanismo son apelativos igualmente empleados al evaluar a los colectivos judíos entre finales del siglo XIX y 1939 (Miller; Ury, 2015; Gelbin; Gilman, 2017). En este caso los pulsos transnacionales se han relacionado, por ejemplo, con la actitud de numerosos intelectuales judíos centroeuropeos que asumieron un emplazamiento supraterritorial, de tono universalista, pero incorporando un tropo identitario judío. $\mathrm{O}$ en relación con el proyecto sionista cuya meta era Eretz Israel como estado-nación, pero que cristalizó mediante una trama y unas redes de tránsito y solidaridad transnacionales.

Este trabajo desea aproximarse a la intersección encarnada en el sujeto comunista judío durante los años treinta. Como hipótesis estimará que constituyó otra muestra de hibridación transnacional donde confluyeron - en acomodación, tensión o negociación - una identidad de partido, codificada como seña de afirmación fuerte, y unas marcas polimórficas conformadas mediante prácticas o sentimientos atravesados por experiencias personales. En síntesis, el texto se preguntará sí debemos hablar de judíos comunistas o de comunistas judíos, o cuáles fueron sus relaciones con otros proyectos identitarios y de afirmación colectiva como el sionismo. 
Para ello se abordarán algunas claves del canon soviético o de la IC acerca de la cuestión judía, así como de varias organizaciones comunistas como el partido polaco (KPP) y el palestino (PCP), cuyo grueso militante procedía de aquel país y que, en los años treinta, integraba militantes judíos y árabes. Dicho espacio transnacional derivará, en la segunda parte del texto, hacia la España en guerra, estudiándose al colectivo judío polaco integrado en las Brigadas Internacionales (BBII). En dicho contexto se analizará el libro de la periodista polaco-estadounidense Gina Medem Los judíos voluntarios de la libertad, una obra excepcional que proyectó un imaginario simbólico sobre España y sobre el universo antifascista judío en vísperas de la II Guerra Mundial o la Shoah.

La segunda parte del artículo se apoyará en un fondo de medio centenar de egodocumentos (autobiografías y verificaciones) de interbrigadistas judíos polacos. Por cuestiones de espacio su análisis será sucinto. No obstante, estas fuentes deben ser estimadas metodológicamente como soportes privilegiados para entender las percepciones, los valores y las claves de auto-reconocimiento de sus autores. Además, son materiales esenciales para abordar la tipología y articulación de las redes comunistas, ya sean las relativas a los lazos familiares y de amistad, a las generadas a través del tránsito geográfico o a las de contacto o control dentro de las organizaciones comunistas. Pero también se trata de un corpus de compleja valoración dada su fragmentación o por los diversos grados de sofisticación narrativa que presenta. Tampoco debe obviarse su naturaleza como documentación orgánica. Autobiografías y verificaciones se extendieron en los partidos comunistas durante los años treinta como requisito para la afiliación, la promoción o la fiscalización interna. Todo ello condicionó, obviamente, los ejercicios de autorrepresentación.

\section{DisCURSO COMUNISTA Y CUESTIÓN JUDÍA}

Algunas autobiografías internacionales evidenciaron la mixtura entre judeidad y compromiso comunista. El polaco Moshé Zalcman explicó su actividad política entrelazando militancia y cultura yiddish. Fue miembro de la Secretaría Judía del Partido Comunista Francés (PCF) y reconocía haber leído de "Marx, Engels y Lenin todo lo que se publica en hebreo". En cambio, el estadounidense Arnold Raisky (Arnold Reid) eludió en 1938 mencionar sus raíces judías. ${ }^{2} \mathrm{O}$ la dirigente rumana Hannah Rabinsohn (Ana Pauker) suprimió de su autobiografía de 1930 el haber asistido a dos escuelas judías o la memoria de su hermano suicidado (Levy, 2001, p. 61).

Tales casos deben situarse en la ambivalente relación entre estalinismo y 
judeidad. Moshé Zalcman fue detenido en la Unión Soviética en 1937 y deportado al Gulag, aunque probablemente más por su condición de extranjero polaco que por ser judío. El antisemitismo constituía un delito en la legislación soviética y la república autónoma de Birobidzhán, creada entre 1928-34 en el Extremo Oriente, fue presentada por la propaganda como solución integradora en el marco de la patria multinacional del socialismo. Hannah Arendt consideró esa estrategia como una respuesta frente al antisemitismo, aunque no como una opción formulada "por judíos para los judíos". Dicha consideración se inscribió en sus reflexiones críticas sobre el asimilacionismo y el sionismo. La "tragedia alemana" evidenciaba los límites del primero, mientras que el segundo se desvelaba incapaz de "representar los intereses judíos a escala global”. Arendt respaldó en 1935 los esfuerzos de la organización sionista Juventud Aliyá. Pero en 1937 consideró que ante el rearme antisemita - en Alemania, Rumania y Polonia; o en España, "país en el que no hay judíos ni cuestión judía”, pero donde Franco "profiere eslóganes antisemitas" -, el sionismo abandonaba todo esfuerzo de resistencia, mientras que insistir en el lema del "regreso" ponía en peligro "a los judíos de todas las naciones, incluida Palestina” (Arendt, 2009, p. 110-113, 119, 128 y 134).

Fijar la república hebrea soviética a miles de kilómetros de los principales focos judíos sería una muestra de la ambivalencia antes mencionada. Como lo fue la variable permisividad gubernamental soviética hacia la judeofobia popular (Shternshis, 2006). La existencia de ámbitos de sociabilidad judía en los partidos comunistas presentó, por su parte, modulaciones diversas. El Partido Comunista de Argentina (PCA) contó con secciones como la Yevsektsya, dirigida a captar asquenazis europeos. Su lengua fue el yiddish e impulsó clubes deportivos (arbeter club) o escuelas infantiles (arberter shuln). ${ }^{3}$ El PCF también dispuso de estructuras para la inmigración judía, un colectivo de casi 60.000 personas en 1939. No faltaron la propaganda específica - como el periódico Naïe Presse -, o los contactos con organizaciones socialistas (bundistas) o cercanas al sionismo, como Poale Zion (Zaagsma, 2017, p. 33-34). Aunque el PCF ensayó como estrategia asimiladora la homogeneidad formativa: en 1936 contaba con escuelas de cuadros para afiliados judíos donde aplicó las programaciones empleadas en las escuelas ordinarias, añadiendo alguna lección sobre "partidos judíos adversos". ${ }^{4}$

Por su parte, la IC situó su relato sobre la cuestión judía dentro de las narrativas antifascista y anti-trotskista. El antisemitismo nazi fue abordado simplificadamente, entendiéndole como señuelo nacionalista "para apartar a las masas de la lucha por sus verdaderos intereses". Dado que el fascismo cons- 
tituía "la forma más reaccionaria del capitalismo", el nazismo exacerbaba la "cuestión judía [en su] límite más extremo". Se calificó la situación en Alemania o Austria como de "exterminio" en un marco de competencia capitalista. Frente a ello solo la Unión Soviética aseguraba la "integración orgánica”. Ahí "las diferencias entre los judíos y el resto de la población desaparecen" según "la religión agoniza". El resultado era una asimilación de nuevo cuño, "los judíos [como] hombres completamente socialistas" decididos a defender su "patria soviética" (Fürnberg, 1938, p. 108-124).

La publicística anti-trotskista insistió, por su parte, en una alianza entre Trotsky y Hitler considerando a la Gestapo como foco irradiador de una red de saboteadores, espías y terroristas. Trotsky fue definido según el viejo imaginario de la judeofobia religiosa ("Judas Trotsky"), aunque también como intrigante jesuita (Lanci, s. f., p. 42; "El camino...”, 1937). Los objetivos de dicha alianza - la ocupación alemana de Ucrania, la restauración del capitalismo en Rusia - permitían obviar cualquier contradicción racial. “iQué más da aliarse con Trotsky o con Rádek siempre que se continúe tratando a sus semejantes como peste judía! Cuando llegue el momento, de una patada se desembarazarán de estos aliados" (Fischer, s. f., p. 8).

Ocasionalmente se pulsó el antisemitismo nazi. Un informe llegado a la dirección del PCF en 1938 transcribió las opiniones de un miembro de las Juventudes Hitlerianas sobre la participación de Alemania en el Congreso Mundial de la Juventud. Según la informante al partido, su interlocutor "no mencionó la presencia comunista como obstáculo principal, sino que ese obstáculo son los judíos”. Para el joven nazi "el problema judío" se resumía en conspiración de una "comunidad internacional criminal". Otra muestra de ambivalencia se evidenció en un informe de la Secretaría Ejecutiva de la IC posterior al pacto germano-soviético. Apuntó la necesidad de organizar en Polonia "una lucha contra la opresión nacional" que supusiese "el retiro de la Gestapo y las SS, la libertad de los presos [y] la liquidación de los campos de concentración”. Pero no mencionó a la población judía, que quedó invisibilizada. ${ }^{5}$

El rechazo soviético al sionismo se inscribió igualmente en coordenadas ambivalentes. Se ha argüido que tras él existía el temor a un foco desestabilizador interno. Esto parece evidente en el estalinismo tardío, en las campañas contra el cosmopolitismo y el "complot de los médicos". Ambos episodios deben situarse en las estelas de la Guerra Fría, la primera guerra árabe-israelí y el cisma soviético-yugoslavo, otro desafío de tono nacionalista. Pero el antisionismo ya constituyó una marca característica del Partido Comunista Palestino (integrado en la IC en 1924), aunque dicha organización, como hizo la 
Unión Soviética, acabó respaldando la partición del antiguo Mandato y la creación del Estado de Israel en mayo de 1948, cuando Ber Kover (Meir Vilner) estampó su firma en la declaración de independencia. Esa aparente contradicción no ha sido advertida como viraje brusco, sino como paulatina asimilación en sectores del PCP y del Partido Comunista de Gran Bretaña, fundamentalmente desde 1939, del yishuvismo como doctrina que pretendía armonizar oficialismo comunista, inmigración y colonización en Palestina. Fue una tesis latente en la tradición fundacional del PCP, en figuras como Ber Borokhov, y acabó impulsada por el austríaco, naturalizado británico, Issie Panner o por Rajani Palme Dutt (Franzen, 2007).

En cualquier caso, el PCP se caracterizaba a mediados de los treinta por una estrategia revolucionarista y por un discurso de clase anticolonial. Sin embargo, no era más que una pequeña formación ilegal en un abigarrado escenario de fuerzas. Particularmente desde 1936, cuando se consolidó la comunidad inmigrante - el Yishuv, con cerca de 400.000 integrantes frente a una población árabe próxima al millón de habitantes - y se derivó en un contexto de violencia espoleada por el gran muftí Amin al-Husayni (Budeiri, 2010). Otra particularidad del partido estribaba en su composición dual con militantes árabes y judíos principalmente llegados del KPP o del Partido Comunista Alemán (KPD). Ello deparó tensiones por la creciente arabización vivida desde finales de los veinte, encabezada por Hamdi Husseini. En paralelo, algunos cuadros judíos sufrieron los envites de las purgas, como los antiguos dirigentes Isaac Zeliaznik (Joseph Berger-Barzilai), de origen polaco e inicial militancia sionista detenido en la Unión Soviética en 1935, o el ruso Daniel Wolf Auerbach.

La correspondencia entre Moscú y Palestina en 1936-38 evidencia el voluntarismo de interpretar las protestas desatadas desde inicios de 1936 como semillas de una inminente insurrección anticolonial. En esas coordenadas el sionismo fue etiquetado como un fenómeno puramente burgués y la acusación de desviacionismo nacionalista fue motivo de expulsión del partido. Dicha perspectiva influyó en la lógica de las alianzas políticas. Según una carta de aquel año de la dirigencia comunista palestina a Moscú, la estrategia frentepopulista no debía traducirse en acuerdos con el laborista Mapai, liderado por Ben-Gurión, sino en reforzar la influencia en la Histadrut, la central sindical hegemonizada por el sionismo laborista. ${ }^{6}$

Otro informe de agosto de 1937 valoró el Plan Peel. La partición del Mandato británico - la administración temporal reconocida por la Sociedad de Naciones - en dos estados fracturaba la posible emancipación en el marco de una Gran Siria, negaba el derecho de autodeterminación, privaba a la pobla- 
ción árabe de las tierras más fértiles y deparaba un estado marioneta en manos del capital judío y los fusiles británicos, puntas de lanza del imperialismo. El texto oponía las masas árabes y judías, entendidas como todo armónico, frente al "gran capitalismo judío" y su herramienta nacionalista, el sionismo. La retórica comunista reutilizó así una etiqueta característica del antisemitismo tamizada con radicalismo panarabista y antagonismo de clase, desembocando incluso en la tesis de que el sionismo cometía "el mismo crimen contra el pueblo árabe que los soldados marroquíes contra el pueblo español".

Según el discurso del PCP la identidad comunista se fundamentaba en una fraternidad popular contrapuesta a la bicefalia sionismo/colonialismo. Pero tal consideración no impidió reacomodar marcas religiosas en parámetros laicos. Así ocurrió con la apropiación comunista de la fiesta de Hannukah, resignificada en metáfora de revuelta popular. El relato sionista de izquierdas también la redefinió, como hizo con otras celebraciones (Rosh Hashaná, Yom Kippur o Sukkot) (Locker-Biletzki, 2015). El antisionismo comunista se tradujo igualmente en considerar en 1936 a la Aliyá, la emigración judía, como mera invasión. ${ }^{8}$ Buena parte del éxodo europeo a Palestina desembocó en el Mapai. Aunque asimismo participó en Hashomer Hatzair, un grupo juvenil fervorosamente sionista defensor de la colonización, pero además de la solución binacional y de la paridad entre árabes y judíos. Frente a la concepción espiritual de Eretz Israel, Hashomer Hatzair defendía una inmigración sin cortapisas de trabajadores europeos encaminados hacia "una sociedad socialista con igualdad absoluta entre los dos pueblos” (Mayer, 2010, p. 207).

\section{TranSVERSALIDADES JUdÍAS}

La transculturalidad y la transterritorialidad vertebraron la autobiografía del bolchevique Karol Sobelsohn (Karl Rádek) escrita a inicios de los años veinte, donde enfocó su auto-construcción como sujeto gracias a la acción política, la reflexividad y el tránsito. Tuvo en su Lvov natal una educación, "como todos los judíos de Galitzia, [basada] en las fuentes de la literatura clásica alemana con sus ideas humanistas". Pero pronto quedó atrapado por la cultura católica y la historia polaca, por episodios con aura romántica y patriótica como la revuelta campesina de 1846. Ya adolescente contactó con una sociedad de trabajadores sombrereros. "En la vivienda de un panadero judío [...] se guardaban en un armario las obras de los socialdemócratas alemanes". Fue su primer contacto con la publicística revolucionaria (Haupt; Marie, 1972, p. 306).

Rádek enfatizó ciertos aspectos - movilidad, cosmopolitismo -, eviden- 
ciando una identidad híbrida. Ese rasgo ha sido relacionado por Traverso (2013, p. 43-60) con lo que ha llamado la cristalización de la modernidad judía. Un escenario con múltiples derivas, como la relativa asimilación francesa frente a la cultura nacional yiddish superpuesta sobre un espacio multinacional en el Este de Europa (Yiddishkeit), en un contexto jalonado por los pogromos zaristas o por los brotes antisemitas polacos, pero también por los procesos de secularización y crisis de ámbitos tradicionales de sociabilidad (los shtetlekh o kehilot). El éxodo hacia algunas grandes ciudades (Berlín, Viena, Budapest, Praga, Lvov o Cracovia) desembocó tanto en la proletarización como en el encumbramiento social. El espacio germánico compuso, complementariamente, el laboratorio para una cultura judía de tintes nacionales expresados, por ejemplo, en el declarado patriotismo alemán de un sionista como Franz Oppenheimer. La creación de un estado en Palestina podía ser la meta para los judíos del Este, pero no para él, que se consideraba síntesis entre identidad "tribal" judía (Stammesbewusstsein) y germanismo "nacional y cultural" (Traverso, 2005, p. 87-88).

La identidad judía comunista se superpuso en estos complejos parámetros. Ha sido valorada como fruto de una deriva universalista (internacionalista) radical que renegó, a un tiempo, del nacionalismo alemán y de la judeidad, es decir, de la especificidad judía (Traverso, 2013, p. 60-63), una marca donde confluyeron Marx, Rosa Luxemburg, Rádek o el dirigente del KPD Werner Scholem. La presencia judía europea en el movimiento comunista internacional se ha evaluado, a su vez, desde distintas ópticas. Se ha considerado que fue resultado del atractivo ejercido por la polarización política. El magnetismo comunista resultó intenso entre los colectivos judíos polaco, rumano y húngaro, siendo menor entre franceses o británicos (Diner; Frankel, 2004, p. 9-10). Otros análisis han destacado la identificación con el progresismo laico, la deriva radical de sectores intelectuales, la reacción frente a los envites antisemitas o influencias de la cosmovisión religiosa. En este sentido se ha relacionado el comunismo judío polaco con reminiscencias mesiánicas coherentes con una visión trascendental y emancipatoria de la historia (Schatz, 1991, p. 13-16).

El KPP debe enmarcarse, además, en conexión con otras singularidades, como las desigualdades sociales, las tensiones socio-culturales o la difícil armonización de un estado-nación con importantes minorías, entre ellas cerca de tres millones de judíos (1931), alrededor de un 10\% de la población. La presión antisemita formó parte de la estrategia de organizaciones conservadoras o de extrema derecha, correlacionándose con la judeofobia popular de raíz católica. Simul- 
táneamente la comunidad judía polaca presentó múltiples fisuras que incluyeron diferencias de clase, urbanas y rurales, entre ortodoxia (Yiddishe Yidn) y no-ortodoxia (Goishe Yidn), distintos grados de asimilación y de transversalidad ideológica ante los polos izquierda/derecha o sionismo/antisionismo.

El KPP, fundado en diciembre de 1918, contó con una importante presencia de militantes judíos que pudo llegar al 25\% en 1935, cuantía duplicada en las juventudes (KZMP), a los que se sumaba otro $15 \%$ de bielorrusos y ucranianos (Cimek, 2012, p. 51-55). Tal composición ayuda a explicar su antinacionalismo polaco, combinado entre su militancia judía con valores como el rechazo a una tradición religiosa tildada de reaccionaria, la idealización de la Unión Soviética o la exaltación de la lucha de clases como respuesta a la opresión social y sobre las minorías nacionales. Aunque la historia del KPP entremezcló clandestinidad, disensiones y presiones desde la Unión Soviética. Acabó disuelto en agosto de 1938 al considerarse que estaba contaminado por la infiltración policial y por la disidencia trotskista. Se ha estimado que fue una medida de precaución en vísperas del pacto germano-soviético ante el temor a un rechazo al mismo. Pero esta hipótesis fuerza los tiempos entre el desmantelamiento del partido y el entendimiento entre Berlín y Moscú, probablemente asumido por Stalin en la primavera de 1939. La disolución más bien debería correlacionarse con la percepción soviética de Polonia como foco desestabilizador, con la credibilidad dada a los informes sobre espionaje, las constantes fricciones vividas en el KPP y con el contexto general de las purgas. De hecho, antes de la disolución fueron detenidos en la Unión Soviética varios dirigentes de primer nivel, entre ellos su secretario general Julian Leszczyński (Lenski).

\section{Pluralidad de sujetos}

La Guerra Civil española provocó diversas reacciones al otro lado del Mediterráneo, en Palestina. Aunque el Mapai o la Histadrut se opusieron a enviar voluntarios, promovieron actos de apoyo a la España republicana. Paralelamente, sectores sionistas conservadores se alinearon con los sublevados. Zvi Kullitz, un publicista cercano al fascismo, defendió en octubre de 1936 el carácter anticomunista de la sublevación y que Franco no era antisemita. La posición opuesta estuvo encarnada en el PCP que suministró afiliados a las BBII, el cuerpo multinacional impulsado por la IC. El mismo objetivo fue planteado por Poale Zion, que mantuvo contactos con el antiestalinista Partido Obrero de Unificación Marxista (Rein, 2009, p. 93-100).

La bibliografía ha resaltado la notable presencia judía en las BBII. Es posi- 
ble que en el contingente llegado a España entre 1936-38 (35.000-40.000 voluntarios) el volumen de judíos sumase 10.000 efectivos, alcanzando quizá la mitad de los 4.000 polacos presentes en España, en su mayoría procedentes de Francia y Bélgica. Por el contrario, el monto venido de Palestina, muchos también de origen polaco, se limitó a pocos centenares (Zaagsma, 2017, p. 22-26).

La IC estableció que los emigrados debían integrarse en la sección nacional del país donde se encontrasen. Esa lógica se aplicó en las BBII desde enero de 1938 al producirse la integración en el Partido Comunista de España (PCE). Tal decisión pretendía optimizar la coordinación y el control político, o neutralizar tensiones entre nacionalidades. Durante ese año se transfirieron alrededor de 2.000 interbrigadistas, provocando un aluvión de fichas y autobiografías. Dicho material permite aproximarnos a sus esferas identitarias, a su autorrepresentación, al sentido de ser judío comunista, al ideal del óptimo militante o a los criterios de valoración y fiscalización orgánica.

Con frecuencia las autobiografías de los judíos polacos eran de pocas líneas. Jakob Izraelson solo consignó, por ejemplo, el nombre de sus padres, su profesión (carpintero) y el haber venido "para defender la República española”. Izrael Pencyna aludió a una razón menos idealista para justificar su marcha a Francia en 1928: "todos los gastos los costeó mi padre, deseoso de tener una boca menos que alimentar". Hijo de un comerciante, fue educado en escuelas católicas y judías. El ideal antifascista, pero también el pragmatismo profesional, fue destacado por la estudiante Ester Zilberberg. Emigrante en Bélgica desde 1929, apuntó que al conocer las noticias de España "comprendí que como comunista, como antifascista y como futuro médico mi deber era marchar". ${ }^{9}$

Otros textos emplearon enfoques más sofisticados sobre la experiencia. Hercel Orzech rememoró su infancia y juventud remarcando sus raíces judías y su formación en el entorno del sionismo. Tras militar en Poale Zion desembocó en la KZMP, aunque centró su autobiografía en España, donde llegó en abril de 1937 integrándose después en la Unidad Botwin, el destacamento formado por un centenar y medio de interbrigadistas judíos polacos. En contraste, Adolf Goldgewicht neutralizó sus raíces judías resaltando como referente identitario a su padre. Lo evocó como propagandista anti-zarista durante la Gran Guerra y como voluntario contra "los generales blancos". Con solo diez años, en 1924, “[le] ayudaba en el trabajo de partido" en la dirección del KPP. Estando en Bélgica, llegó la posibilidad de venir voluntario a España, "que era, en realidad, nada más que cumplir mis sueños de muchos años”. ${ }^{10}$

La autobiografía de Goldgewicht superponía la identidad comunista a posibles señas de especificidad judía, anulándolas. El mismo argumento figu- 
ró en otros relatos donde transterritorialidad era sinónimo de internacionalismo y donde el particularismo judío se sustituyó por reflexión sobre los orígenes de clase o por conciencia de explotación. Así ocurrió en la autobiografía de Alja Zaydor, un cuadro comunista intermedio, donde la auto-construcción del sujeto era consecuencia de factores sociales y de decisiones personales. Remarcó sus orígenes proletarios o su vasto periplo como estudiante (Francia, Bélgica, Italia, Suiza), junto a una conciencia fruto de las lecturas ("me interesé vivamente por los problemas marxistas") y una militancia en organizaciones de base, de agitación entre emigrados polacos y como alumno en una escuela del PCF. En su relato, la acción política lo monopolizaba todo anulando incluso su esfera privada, limitada a media línea de texto ("En Lausana me casé con una camarada"). ${ }^{11}$

Otro tanto cabe decir de la autobiografía de Elías Hilsenrad. Ya en el encabezamiento se definió como "funcionario del partido". Asimismo resaltó no haber militado en ninguna otra formación, no haber sido "nunca castigado" y no haberse opuesto nunca a la "línea del Partido". Dicho énfasis quizá pueda explicarse como correctivo frente a sus raíces familiares, de clase media polaca. Hilsenrad emigró por estudios a Brno, donde se convirtió en un responsable comunista local. Un ejemplo más de autobiografía que velaba cualquier singularidad judía fue la de Simon Eicher, a pesar de ser un promotor de la Unidad Botwin: de nuevo se trataba de un estricto historial militante donde dibujaba, en clave comunista, su entorno familiar - sus padres, trabajadores en Vilna; su hermano, miembro del partido emigrado a la Unión Soviética - o su peripecia vital - abandono de la escuela, trabajo como aprendiz, detenciones y encumbramiento orgánico. ${ }^{12}$

En otros casos el relato autobiográfico agrupó sucesivas narrativas fruto de la investigación de interbrigadistas sospechosos. Así ocurrió con el médico polaco Osias Zellermeyer (Jerzy Zeller) en 1938. En una apuntó haber participado en una organización juvenil sionista, aspecto después eliminado al mencionar solo el ingreso en las juventudes comunistas durante sus estudios en Bratislava. Aunque siempre intentó aproximarse al canon del buen militante, enfatizando su trabajo militante y sus detenciones, o reflexionando sobre el papel formativo del partido ("se ha vuelto abierto y más humano para mí. La comprensión sobre responsabilidades en el Partido se ha vuelto mayor y la comprensión de la dialéctica también"). Tales afirmaciones eran respuestas a la fiscalización interna. Zeller fue objeto de una larga verificación plagada de acusaciones como haber mentido, carecer de "desarrollo político o moral", ser "orgulloso, pedante [y] aventurero" o de simpatizar con el fascismo. El pare- 
cido físico con un militante nazi norteamericano llevó, incluso, a sospechar que era un infiltrado. ${ }^{13}$

La etiqueta de pequeñoburgués se empleó, por su parte, contra el médico polaco Samuel Flato. Miembro del PCF desde 1932 y con responsabilidades en el secretariado de la Juventud Comunista Judía, llegó a España en diciembre de 1936. Concluyó su autobiografía asegurando no haber recibido "nunca ningún reproche”. Las apreciaciones realizadas sobre él en España resaltaron su entusiasmo y valor. En cambio, ya en Moscú en 1940, fue objeto de una valoración negativa donde se afirmó que mantenía "restos de su medio social pequeñoburgués” y “tendencias trotskistas”. Quizá llegase a ser algún día un cuadro comunista, se concluía, "aunque necesita ser educado y someterse a control continuo". ${ }^{14}$

Dicha evaluación debe relacionarse con las sospechas contra muchos militantes polacos traducidas mediante un antisemitismo elemental sobre el intelectual ocioso que encubriría al enemigo de clase. Pero podían existir otras zonas oscuras. Isaac Landsmann trabajó como intérprete para los soviéticos hasta ser despedido en 1938 "por no ser claro su pasado". Alegó ser miembro del KPP desde 1920. "Interrogado más estrechamente [...] declaró que tal vez [solo fue] miembro del Socorro Rojo Internacional”. Samuel Joselewsky - antiguo bundista polaco, militante del KPD - afirmó haber colaborado con la Checa, extremo que los archivos soviéticos negaban. Mantener una relación familiar con la NKVD tampoco evitó la investigación. Zachar Rafalowicz, un ingeniero polaco emigrado a la Unión Soviética, resaltó en su ficha de afiliación al PCE que su mujer trabajaba en Moscú en ese organismo. No obstante, en 1938 se le tildó de "bastante sectario". En su verificación de 1940 se recordó que "sobre su pasado muchos camaradas nos previnieron de que existían cosas poco claras". ${ }^{15}$

Estas mecánicas de control reflejaban el ideal de partido bolchevizado que verificaba antecedentes y seleccionaba cuadros, ideológicamente homogéneo y temeroso de la infiltración, extremos proyectados intensamente sobre las BBII (Kirschenbaum, 2015, p. 131-150). Ello derivó en la frecuente redacción de aclaraciones por parte de interbrigadistas investigados. Chaim Jungman, que vivió en Argentina, redactó un informe donde justificaba las carencias de su primera autobiografía ("cuando pasé la frontera española me plantearon la cuestión de la biografía en tal modo que temía ser enviado de vuelta”), aclarando extremos como su militancia en Poale Zion o su participación en una disidencia en el PCA a mediados de los años veinte al caer "bajo la influencia de los del Grupo Israelita". ${ }^{16}$ 
Al cumplimentar su ficha como afiliado del PCE Jungman afirmó poseer nacionalidad judío-polaca, Flato se definió como polaco y Zaydor como apátrida. Tal diversidad se reiteró también entre interbrigadistas de origen polaco procedentes de Palestina: David Kamy consignó ser palestino mientras que Max Kaver, Marcel Lenger o Aron Tenenbaum indicaron ser judíos. Ariel Hollander, nacido en Berlín, se identificó en cambio como inglés-palestino. No obstante sus perfiles eran bastante similares. Nacidos entre 1903 y 1917, poseían formación académica o técnica y contaban con un nutrido historial activista. Kamy decía estar buscado por la policía de Haifa y haber pasado a la clandestinidad. Kaver estuvo afiliado en la Histadrut hasta su expulsión en 1932 por "organizar una huelga contra la voluntad sindical”. Lenger era, por su parte, un viejo miembro del PCP y Tenenbaum militaba en las juventudes y en el Geserd, el organismo soviético para el asentamiento en Birobidzhán. Sin embargo, años atrás formó parte de la sección polaca de Hashomer Hatzair mientras que Kamy participó hasta 1928 en un grupo deportivo sionista. Aunque el paradigma biográfico probablemente estuvo encarnado en Abraham Rosenzweig. Afiliado del PCP desde 1921, participó en varios comités locales y en la dirección central. Deportado por las autoridades británicas llegó a España desde Bélgica, donde ejerció una activa labor propagandística como responsable de un periódico en yiddish para inmigrantes. ${ }^{17}$

Las autobiografías de interbrigadistas venidos de Palestina permiten enfocar los motivos de la emigración o la identidad comunista judía en el Yishuv. El polaco-ucraniano Hercel Wecksler escribió que su padre, de fuertes convicciones sionistas, decidió la marcha familiar a Palestina. Allí estudió en la Universidad Hebrea, ingresando en 1931 en el PCP. Fue arrestado en diversas ocasiones por las autoridades británicas hasta acabar deportado a Polonia en 1935. La familia de Joseph Wajsblum emigró en 1924 tanto por la "mala situación económica y el antisemitismo" como por "las ideas sionistas" del progenitor. Su primera militancia fue en Hashomer Hatzair, de donde se escindió una facción que acabó en el PCP en 1926. Otro interbrigadista polaco, Samuel Benmordchaj, consignó haber partido a Palestina en 1920, donde militó en la organización socialista Ahdut ha-Avodá, ingresando en 1928 en el PCP. Después actuó como responsable orgánico en Haifa y Jerusalén. Cerró su historial afirmando orgulloso que, por su "trabajo revolucionario, el gobierno de Palestina me ha descalificado en el año 1933 como ciudadano". En su ficha de inscripción al PCE de 1938 apuntó ser "judío sin nacionalidad”. ${ }^{18}$ 


\section{JUDEIDAD Y ESPAÑOLIZACIÓN SIMBÓLICA}

La creación de la Unidad Botwin se justificó en clave transnacional, por su eco propagandístico "de socorro y reclutamiento para la República española entre las grandes masas judías", pero asimismo para "organizar y relativamente controlar" a los interbrigadistas polacos. El temor a la infiltración sionista también se reflejó en 1938 en el PCE. Durante una discusión en una célula, un interviniente recordó la trascendencia de la investigación biográfica. Apuntó que dos oficiales judíos habían "estado desde los primeros años hasta 1934 en una organización contrarrevolucionaria sionista". Por tanto, "me debían decir toda su historia". ${ }^{19}$

Las actitudes ante el antisemitismo fueron, asimismo, ambivalentes. Solo los voluntarios judíos de la Brigada Dombrowsky condenaron las persecuciones en Polonia afirmando que eran fruto del "régimen fascista" y "completamente extrañas al pueblo". En cambio, en un informe sobre la situación de su brigada a mediados de 1937, un comisario político explicó la presencia de brotes antisemitas arguyendo la responsabilidad judía. Ellos "tienen la culpa [pues hay algunos] que al poco de estar en el frente se cansan y otros que no son disciplinados". Aunque algún improperio antisemita fue igualmente objeto de pesquisa y sanción. Alexander Romanjuk fue denunciado por sus virulentos exabruptos ("judíos, hijos de puta, hace falta un Hitler para ellos") y acabó detenido. Ser antisemita se estimó también, en alguna verificación realizada en Moscú en 1940, como indicador de debilidad política e infantilismo ideológico. Stefan Podima, por ejemplo, fue evaluado como interbrigadista "regular", con "actividad política nula" y "analfabeto político con tendencias antisemitas". ${ }^{20}$

La conexión pública más notable entre sentimiento nacional, judeidad, identidad comunista y españolización antifascista estuvo representada, por el contrario, por el folleto Los judíos voluntarios de la libertad de la periodista Gina Medem, editado a finales de 1937. Nacida en 1886 en una familia de clase media, colaboró con grupos socialistas de Lodz. Durante sus estudios conoció al letón Vladimir Medem, un ideólogo del bundismo con quién se casó en 1912. En 1921 arribó a Estados Unidos. Allí se convirtió en activa publicista de la cuestión judía, visitando Birobidzhán en varias ocasiones. Inició su militancia comunista en 1930 y permaneció en España entre 1937-1938 como reportera de la revista neoyorquina New Masses.

Concebida como crónica sobre la presencia judía en las BBII, la obra de Medem aunó judeidad y guerra de España trazando un retrato mediante recur- 
sos ejemplarizantes y la exaltación heroica. A través de una retórica épica, la obra se estructuraba en pequeños capítulos sobre la interacción entre sujeto judío, lucha española e ideales antifascistas. El primero era presentado como colectivo errante y víctima histórica de la intolerancia inquisitorial, aunque no tenía "rencor hacia las masas españolas" puesto que "el pueblo no participó en esa barbarie prefascista", manejando así una imagen anacrónica del antisemitismo como constructo burgués. Llegados al presente, Medem resaltaba la naturaleza transnacional del sujeto judío alejado del gueto, con aspiraciones universalistas, "mártir de los países fascistas" y del que se derivaban "fuerzas progresivas" o un sentimiento de "solidaridad con sus hermanos españoles".

Complementariamente Medem (1937, p. 7-18) incluyó varias biografías de tono heroico para personalizar el canon del óptimo militante como parábola de ese compromiso judío antifascista, o bien en clave de martirologio laico, un género profusamente empleado en la propaganda comunista. El resultado era una galería que fusionaba judeidad, implicación comunista e identificación con España, con nombres como los caídos polacos Drukula Kata, Maurice Aizenberg, Bobrus Nissenbaum o Josef Rubinstein. Sin embargo, el texto armonizaba también, en algún caso, raíces sionistas e identidad comunista, al apuntar que Rubinstein había participado en una "organización judía deportiva [Maccabi], [...] creada por la juventud nacionalista”, aunque sin separarse del "medio obrero".

Los testimonios recogidos por Medem exaltaron las imágenes de valentía judía y hermanamiento internacional. En otros pasajes relató episodios de arrojo y compromiso, como el de Chaim Raszelbuch, de quien subrayó el esfuerzo ("trabajaba dieciséis horas diarias"), el enfrentarse a un antisemitismo cotidiano o su heroísmo en el frente y la retaguardia, donde fomentó "el trabajo cultural, las fiestas conmemorativas [o] las guarderías infantiles" (Medem, 1937, p. 31-39).

Tampoco faltaron en el texto las alusiones a la experiencia de Birobidzhán, cuya capital "había sido construida por trabajadores judíos". La solución soviética se presentaba como "única salida y camino a seguir". Sin embargo, al reseñar la biografía de un interbrigadista procedente de Palestina (Itzhak Yoffe), Medem apuntó que la Aliyá representaba igualmente "la única solución para los judíos perseguidos por los gobiernos fascistas y antisemitas”. El Yishuv constituía un asentamiento en "el país histórico [para establecer] un gobierno democrático". A esta potencial dualidad del hogar judío - Birobidzhán y Palestina -, Medem sumó su reflexión sobre las diferencias entre "patriotismo particular" y "sentimiento nacional". Este permitía explicar tanto la identidad 
nacional judía como el nacionalismo antifascista español propugnado por el PCE que consideraba la guerra como lucha de independencia frente a la agresión extranjera y el sentimiento nacional en "amor profundo y patético hacia [...] la España democrática" (Medem, 1937, p. 12-19, 39, 58-59 y 73-74).

Los judíos voluntarios... debe interpretarse como un ejercicio de ensamblaje identitario. Ese era el valor otorgado a la Guerra Civil, pero también a la colectividad judía como sujeto nacional transterritorial. Ambas identidades - judía y española - eran compatibles, reforzándose mutuamente gracias a otra marca integradora: la transnacional comunista sintetizada en las BBII. El antifascismo, como cultura igualmente internacional, aportaba finalmente el encuadre y la justificación compartida de luchar contra el enemigo común.

Aunque Los judios voluntarios de la libertad fue un encargo de Luigi Longo, Comisario Inspector de las BBII, Medem pronto cayó en sospecha. Durante la redacción del libro se pidió información desde el Comité Provincial de Madrid a la dirección del PCE y en una primera verificación, a mediados de 1938, se recordaron sus antecedentes bundistas o que algunos de sus contactos en Birobidzhán estaban detenidos. Medem tenía "grandes habilidades periodísticas, [pero] políticamente es débil y una demagoga”. Otra verificación de 1940 retomó tales antecedentes. Apuntó que existían "fuertes sospechas". "Nos dijeron que durante los últimos meses de su estancia en España estaba desmoralizada. [...] Salió del país un mes antes de que comenzásemos a investigarla". Ya en 1941 se la relacionó con dirigentes del KPP sospechosos de nacionalismo e influencias sionistas, que "organizaron reuniones" con "presencia de elementos trotskistas". Tal disidencia habría estado encabezada por el comisario político Gustaw Reicher (Rwal), detenido y ejecutado en la Unión Soviética en 1938, y por Gershon Dua-Bogen, antiguo emigrante en Palestina, inspirador del PCP y también comisario en España. De hecho, a inicios de 1938 se le acusó ya de encabezar una red dedicada al sabotaje - "escapar del control del p[artido] y recibir prensa socialdemócrata y burguesa" - o al "trabajo incontrolado entre [los] cuadros". ${ }^{21}$

\section{CONSIDERACIONES FINALES}

Este trabajo ha resaltado al sujeto judío comunista de los años treinta como constructo histórico. Al inicio de estas páginas se planteó si hemos de hablar de judíos comunistas o de comunistas judíos. Si dicha pregunta se formula buscando respuestas absolutas resulta capciosa, cuando no errónea. En cambio, si se relativiza - pasando de la identidad unívoca a las identidades 
plurales o, más aún, a las identificaciones - apuntaría a un fenómeno, más ambiguo, de interacción. Ya en Israel, en los ochenta, el antiguo interbrigadista Shlomo Szein recordaba que, con frecuencia, le preguntaban si fue a España como comunista o como judío. "Era una cuestión ridícula", argumentó. "Yo era comunista, lo cual determinaba básicamente mi visión del mundo [...]. Pero, ¿significaba esto que tenía que deshacerme de mi judeidad? Después de todo, el reclutamiento para España se basaba en el antifascismo." Otro interbrigadista, Jonas Brodkin, razonó en términos similares: "Mi compromiso con España fue sobre todo un compromiso contra el fascismo. Tenía una doble motivación, si se quiere, como comunista y como judío, nacido en Palestina. [...] El sentimiento nacional judío era fuerte en mí, y el odio al fascismo era natural" (Brossat; Klingberg, 2016, p. 102).

Las autobiografías de partido y la obra de Gina Medem coincidieron en ese carácter declaradamente antifascista. Pero también fueron receptáculos heterogéneos para la representación del sujeto, la articulación discursiva de las experiencias, la posible expresión de la judeidad o el acoplamiento entre relato vital y canon comunista. Según las narrativas oficiales soviética y de la IC las identidades judía y comunista constituían esferas formalmente ensamblables, aunque asimétricas. Sin embargo, en la práctica estuvieron sometidas a diversas situaciones de acomodo, tensión y negociación en su gestión narrativa. La judeidad podía ser una marca transnacional que permitía apelar a raíces o rasgos compartidos, según subyacía en el libro de Medem junto a su evidente yishuvismo. O bien quedar neutralizada, como manifiestan muchas autobiografías donde el peso de la militancia comunista anuló otras especificidades identitarias. En numerosos relatos figuraron claves compartidas - exclusión de componentes religiosos o de alusiones a la vida privada; compromisos construidos a través de historiales activistas y sindicales -, junto a diversos grados de formación política, de experiencia orgánica o de conciencia y afirmación del hecho de la judeidad.

Desde el prisma de la IC identidad comunista era sinónimo de identidad fuerte. Un reflejo de ello fue estimar que la cuestión judía era un problema resuelto en la Unión Soviética gracias a una socialización pivotada en factores inclusivos (ciudadanía y patria socialista). Por otra parte, que algunas autobiografías de interbrigadistas estuviesen redactadas en castellano permite sugerir la idea de una identificación con España, cuestión enfatizada en el libro de Medem. Muchos interbrigadistas judíos polacos afirmaron conocer el castellano y sus autobiografías son manuscritos autógrafos, no traducciones. No obstante, también debe resaltarse que tales relatos ofrecieron una imagen del 
país como telón de fondo o rol emotivo de apelación antifascista, y que resultará necesario reflexionar acerca del uso del castellano como recurso idiomático o marcador de identidad en esos ejercicios de autorrepresentación.

Otro aspecto formulado al inicio de este artículo es el de las relaciones con el sionismo. De nuevo debe diferenciarse entre discurso oficial de la IC y casuística personal. La huella de origen o la primera militancia de muchos judíos comunistas - en este sentido las BBII sirven de ecosistema representativo - fue el compromiso sionista. Un compromiso férreamente censurado por el discurso cominterniano en coherencia con su tradicional crítica al chauvinismo o, en el caso de las BBII, a los grupúsculos nacionales. Pero que también podía ser paradójica ante la posición mantenida frente a otros contextos, como Checoslovaquia, que pasó de considerarse una ilusión nacional burguesa a asumirse la tesis del derecho a la autodeterminación, incluyendo la fractura territorial (Fowkes, 2008).

El PCP puede entenderse como microcosmos de las contradicciones antisionistas al ser una pequeña formación clandestina con un complejo componente binacional que acabó desembocando en dos organizaciones (judía y árabe). No debe olvidarse tampoco la perspectiva sugerida por Halpern y Reinharz (2000, p. 268-306) acerca del Yishuv como laboratorio político-ideológico y marco para una intensa competición entre grupos de izquierda radical. Un mosaico de tendencias definido por la tensión y por la necesidad de lograr intersticios de influencia para intentar disputar la hegemonía al sionismo laborista. Ahí se situó la militancia comunista nutrida por inmigrantes básicamente centroeuropeos, si bien muchos compartieron el ideal sionista del hogar nacional.

Aunque los materiales autobiográficos vuelven a evidenciar situaciones diversas. Jonas Brodkin y Sara Wajsblam representaron dos de los escasos ejemplos de interbrigadistas nacidos en Palestina. Militantes del PCP, desde 1927-28, hicieron la ruta opuesta a la Aliyá, marchando a Francia. Por su parte el polaco-ucraniano Wolf Dain (Bayan) emigró a Palestina a inicios de los veinte imbuido por el discurso sionista de izquierdas, pero después marchó a Alemania, integrándose en el KPD y en otros colectivos de sociabilidad judía. Tras el ascenso de Hitler al poder acabó exiliado en Francia. En su caso la deriva del sionismo al comunismo parecía un tránsito perfectamente natural. Afirmó en su autobiografía que desde niño se sentía sionista y que participó en Palestina en varias colonias agrícolas hasta acabar en un kibutz basado en la "más absoluta colectivización". 22

Otro interbrigadista, el ruso David Ostrowski, reconoció que durante los 
años treinta mantuvo la doble afiliación en el PCP y Hashomer Hatzair (Ibáñez-Sperber, 2006, p. 107). Fue investigado en España y desde el PCP se le tildó de intrigante y "desmoralizador de la juventud". Mendel Kriestler, en cambio, se vanaglorió en su autobiografía de haber denunciado el programa "sionístico-faccioso" de la primera organización judía donde militó, por lo que fue expulsado. Por su parte, el rumano Isaac Simonovic también formó parte de una organización sionista, cauce que le permitió ir a Palestina en 1933. Allí no se afilió al PCP sino a una agrupación deportiva obrera de tintes nacionalistas. Su militancia comunista no tuvo lugar hasta 1938, ya en las filas del PCE. Aunque tan cercanos antecedentes sionistas no le impidieron ser evaluado en 1941 como "buen camarada". La misma apreciación logró Moiscez Lewi, otro polaco con responsabilidades orgánicas en Tel Aviv, a pesar de que acabó excluido del PCP por "desviaciones nacionalistas". Finalmente, otras autobiografías evidenciaron distancias tanto frente al judaísmo religioso tradicional como al sionismo. La polaca Rachel Luftig recalcó en su ficha para el PCE que sus padres eran laicos, apolíticos y que estaban unidos mediante "matrimonio libre". ${ }^{23}$

Este texto se ha aproximado a una generación compacta aunque ambivalente. Cabe leer Los judios voluntarios de la libertad como crónica sacrificial judía en España. Muchos interbrigadistas acabaron siendo víctimas del nazismo. Goldgewicht fue enviado a Mittelbau-Dora y murió poco después de la liberación. Kamy fue apresado, torturado y asesinado en Bélgica. Y Tenenbaum, Kaver o Lenger fueron deportados desde Francia a campos de exterminio. Todo ello no debe hacernos olvidar que también fue una generación, en gran parte, perdida.

\section{REFERENCIAS}

ARENDT, Hannah. Escritos judíos. Traducción: Miguel Candel. Barcelona: Paidós, 2009.

BROSSAT, Alain; KLINBERG, Sylvie. Revolutionary Yiddishland: A History of Jewish Radicalism. London: Verso, 2016.

BUDEIRI, Musa. The Palestine Communist Party 1919-1948: Arab and Jew in the Struggle for Internationalism. London: Haymarket, 2010.

CARLAVILlA, Mauricio. Sodomitas. Homosexuales. Políticos. Científicos. Criminales. Espías, etc. Madrid: Nos, 1973.

CIMEK, Henryk. Jews in the Polish Communist Movement, 1918-1937. Studies in Politics and Society, Warsaw, v. 9, p. 42-57, 2012. 
COMÍN, Eduardo; BOTZARIS, Alejandro. Comunismo y masonería. Segovia: FET de las JONS, ¿1952?

DINER, Dan; FRANKEL, Jonathan. Introduction. Jews and Communism: The Utopian Temptation. Studies in Contemporary Jewry, Oxford: Oxford University Press, v. 20, p. 3-11, 2004.

DULLIN, Sabine; STUDER, Brigitte. Communism + Transnational: The Rediscovered Equation of Internationalism in the Comintern Years. Twentieth Century Communism, Chadwell Heath, v. 14, p. 66-95, 2018.

EL CAMINO de Judas: el traidor Trotsky o Acta de acusación contra los agentes de Trotsky. s. l.: Europa-América: 1937.

FISCHER, Ernst. jAniquilad el trotskismo! s. l.: Europa-América, s. f.

FOWKES, Ben. To Make the Nation or to Break It: Communist Dilemmas in Two Interwar Multinational States. In: LAPORTE, Norman et al. (ed.). Bolshevism, Stalinism, and the Comintern: Perspectives on Stalinization, 1917-1953. London: Palgrave, 2008. p. 206-224.

FRANZEN, Johan. Communism versus Zionism: The Comintern, Yishuvism, and the Palestine Communist Party. Journal of Palestine Studies, Institute for Palestine Studies, v. 36, n. 2, p. 6-24, 2007.

FÜRNBERG, F. La cuestión judía y el antisemitismo. La Internacional Comunista, s. l., p. 109-124, dic. 1938.

GARRAIO, Júlia. Hordas de violadores: a instrumentalização da violência sexual em discursos anticomunistas alemães da Guerra Fria. Revista Crítica de Ciências Sociais, Coimbra: Universidade, v. 26, p. 47-66, 2012.

GELBIN, Cathy; GILMAN, Sander L. Cosmopolitanisms and the Jews. Michigan: University of Michigan Press, 2017.

GRÍCOLI, Zilda Márcia. Intolerância e resistência: a saga dos judeus comunistas entre a Polônia, a Palestina e o Brasil, 1930/1975. São Paulo: Humanitas; Itajaí: Ed. Univali, 2004.

HALPERN, Ben; REINHARZ, Yehuda. Zionism and the Creation of a New Society. London: Brandeis University Press, 2000.

HANEBRINK, Paul. A Spectre Haunting Europe: The Myth of Judeo-Bolshevism. Cambridge, MA: Harvard University Press, 2018.

HAUPT, Georges; MARIE, Jean-Jacques. Los bolcheviques. México: Era, 1972.

IBÁÑEZ-SPERBER, Raquel. Judíos en las Brigadas Internacionales: algunas cuestiones generales. Historia Actual On-Line, Cádiz: Universidad, v. 9, p. 101-115, 2006.

KERSFFELD, Daniel. Rusos y rojos: Judíos comunistas en los tiempos de la Comintern. Buenos Aires: Capital Intelectual, 2012.

KIRSCHENBAUM, Lisa A. International Communism and the Spanish Civil War: Solidarity and Suspicion. Cambridge, UK: Cambridge University Press, 2015. 
LANCI, P. La alianza del trotskismo y del fascismo contra el socialismo y la paz. Madrid: Europa-América, s. f.

LAPORTE, Norman. Introduction: Local Communisms within a Global Movement. Twentieth Century Communism, Chadwell Heath, v. 5, p. 7-20, 2013.

LEVY, Robert. Ana Pauker: The Rise and Fall of a Jewish Communist. Berkeley, CA: University of California Press, 2001.

LOCKER-BILETZKI, Amir. The Holidays of Revolution: Myth, Ritual and Identity among Tel Aviv Communists, 1919-1965. Ontario: University of Guelph Press, 2015.

MARTÍNEZ BANDE, José Manuel. La intervención comunista en la guerra de España: 1936-1939. Madrid: SIE, 1965.

MAYER, Arno J. El arado y la espada: del sionismo al Estado de Israel. Traducción: Ana Escartín. Madrid: Península, 2010.

MEDEM, Gina. Los judíos voluntarios de la libertad (Un año de lucha de las Brigadas Internacionales). Madrid: Comisariado de las Brigadas Internacionales, 1937.

MICHELS, Tony. On Jews and Taboos in American Communist History. American Communist History, London: Routledge, v. 14, n. 3, p. 249-255, 2016.

MILLER, Michel; URY, Scott. Cosmopolitanism, Nationalism and the Jews of East Central Europe. New York: Routledge, 2015.

PIVATO, Stefano. I communisti mangiano i bambini. Bologna: Il Mulino, 2013.

REIN, Raanan. Las repercusiones de la Guerra Civil española en Palestina: sionistas y comunistas, judíos y árabes. Historia Contemporánea, Leioa: UPV, v. 38, p. 89-112, 2009.

REIN, Raanan. Metas nacionales y étnicas en una lucha transnacional: argentinos-judíos en solidaridad con el bando republicano en la Guerra Civil española. Investigaciones y Ensayos, Buenos Aires: Academia Nacional de la Historia, v. 61, 2014.

SCHATZ, Jaff. The Generation: The Rise and fall of the Jewish Communists in Poland. Berkeley: University of California, 1991.

SHTERNSHIS, Anna. Soviet and Kosher: Jewish Popular Culture in the Soviet Union, 1923-1939. Bloomington, IN: Indiana University Press, 2006.

TAL, Tzvi. Santificando a una judía comunista: la reacomodación de la identidad brasileña en Olga (Monjardim, Brasil, 2004). Araucaria, Sevilla: Universidad, v. 15, p. 90-105, 2006.

TRAVERSO, Enzo. Los judíos y Alemania: ensayos sobre la "simbiosis judío-alemana". Traducción: Isabel Sancho. Valencia: Pre-Textos, 2005.

TRAVERSO, Enzo. El final de la modernidad judía: historia de un giro conservador. Traducción: Gustau Muñoz. Valencia: PUV, 2013.

VISACOVSKY, Nerina. Argentinos, judíos y camaradas: tras la utopía socialista. Buenos Aires: Biblos, 2016.

ZAAGSMA, Gerben. Jewish Volunteers, the International Brigades, and the Spanish Civil War. London: Bloomsbury, 2017. 


\section{NOTAS}

${ }^{1}$ Resultado del Proyecto ref. HAR2016-77416-P (MCIU, Gobierno de España).

${ }^{2}$ Archivo Estatal Ruso de Historia Socio-Política (RGASPI), 495/270/1239 y 545/3/453.

${ }^{3}$ Aunque no es objeto de atención aquí, deben recordarse las aportaciones sobre el PCA de Kersffeld (2012), Visacovsky (2016) o Rein (2014). Sobre la inmigración judía comunista en Brasil o su memoria pública véanse Grícoli (2004) y Tal (2006), aunque son temas aún insuficientemente tratados por la historiografía.

${ }^{4}$ RGASPI, 517/1/1811.

${ }^{5}$ RGASPI, 533/10/3356 y 495/18/1301.

${ }^{6}$ RGASPI, 495/14/364.

${ }^{7}$ RGASPI, 495/14/369.

${ }^{8}$ RGASPI, 495/14/369.

${ }^{9}$ RGASPI, 545/6/702, 545/6/755 y 545/6/810.

${ }^{10}$ RGASPI, 545/6/749 y 545/6/691.

${ }^{11}$ RGASPI, 545/6/807.

${ }^{12}$ RGASPI, 545/6/701 y 545/6/681.

${ }^{13}$ RGASPI, 545/6/719.

${ }^{14}$ RGASPI, 545/6/683.

${ }^{15}$ RGASPI, 545/5/731, 545/6/701 y 545/6/763.

${ }^{16}$ RGASPI, 545/6/701.

${ }^{17}$ RGASPI, 545/6/713, 545/6/731, 545/6/792, 545/6/626 y 545/6/769.

${ }^{18}$ RGASPI, 545/6/800, 545/6/797 y 545/6/678.

${ }^{19}$ RGASPI, 545/3/531.

${ }^{20}$ RGASPI, 545/3/218, 545/3/266, 545/6/767 y 545/6/759.

${ }^{21}$ RGASPI, 545/6/742, 545/6/666, 545/6/838 y 545/2/75.

${ }^{22}$ RGASPI, 545/6/626 y 545/6/797.

${ }^{23}$ RGASPI, 545/2/143b, 545/6/626 y 545/6/1551, 545/6/836, 545/6/733 y 545/6/737.

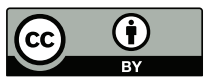

Artículo recibido el 18 de noviembre de 2018. Aprobado el 16 de abril de 2019. 